\title{
Corruption: Greed, Culture, and the State
}

Susan Rose-Ackerman

Introduction

To lawyers, corruption is mainly a problem of law enforcement.

Bribes and other types of corrupt dealings are hard to observe and to prosecute if both sides gain from the transaction, because even clear losers may risk retaliation if they report a transaction. The economic analysis of bribery frequently views it only as a special case of the economic analysis of criminal behavior more generally. 1

This focus on law enforcement begs some interesting questions. The very concept of corruption is contested in some quarters, requiring an analysis of deep questions defining the relationship between state and society. I address these issues in Parts I and II 
by confronting the seemingly disparate views of free market libertarians and of ethnographers who study corruption as an aspect of the relations between state and society. Although their views are fundamentally different in many respects, they are both skeptical of the modern state and frequently see "corruption" as a superior alternative to abiding by the formal law. Next, in Part III, I explore how free-marketeers and cultural ethnographers confront what is called "grand corruption"-involving political leaders and multi-national firms. Here, we see a marked reversal. Corporate interests, which in other circumstances emphasize the value of the free market, here characteristically invoke local cultural practices as an excuse for making payoffs. In contrast, it is the scholars of local cultural practices who invoke the predominance of economic incentives - that is, the greed and the profit motive of multi-national firms-to condemn grand corruption. After confronting these curious convergences and conceptual reversals, Part IV develops my own "democratic legitimacy" approach. It stresses the way pervasive corruption undermines the competence, fairness, and democratic legitimacy of the modern state. It substitutes the criterion of willingness-to-pay for criteria based on desert, need, efficiency, and other values. This approach leads to a suggested reform agenda consistent with the goal of strengthening state 
capacity and accountability.

\section{I. libertarians and corruption}

Libertarians view corruption as a symptom of an intrusive, meddling state that systematically reins in the free market and undermines entrepreneurial activity and competition. Their solution is to reduce the state to its bare bones so that it does little more than protect private property and provide security. They argue that market actors who pay bribes to avoid complying with the rules, to lower tax bills, or to get favors, limit the harm that the state can do and consequently enhance the benevolent operation of the free market as a locus of individual freedom. 2 Although in the libertarian view the best solution would be a drastic cutback in the state, bribery can seem a second-best technique that permits free markets to function in a rough and ready fashion.

Libertarians start with the presumption that the unfettered market is best. They are less concerned with the legality or illegality of quid pro quo deals. The primaryissue is whether the transaction furthers economic freedom. A bribe to get around a costly regulation would be approved, but one to induce the police to harass your 
competitors would not. A natural implication of this approach is that a small government with few responsibilities is best. Gary Becker of the University of Chicago has been a strong advocate of this view with essays titled To Root Out Corruption, Boot Out Big Government and If You Want to Cut Corruption, Cut Government. Work based on the Heritage Foundation's Index of Economic Freedom echoes Becker's libertarian view.One essay notes the correlation between the Index of Economic Freedom and low levels of corruption. The authors "believe economic freedom is intrinsically connected to the level of government activity in an economy. The fewer resources (including assets and regulatory power) a government controls, the fewer the opportunities for corruption." $\underline{4}$

This perspective suggests that the state is a kleptocratic monster that makes no pretense of operating in the interests of its citizens. $\underline{5}$ Laws against bribe-taking by underlings only permit higher-up officials to extract more for themselves. These laws do nothing to further any notion of "good government." Geoffrey Brennan and James Buchanan, for example, borrow Thomas Hobbes's description of the state as a Leviathan and model it as a hungry beast seeking to maximize its control over revenue. For them, taxation and regulation are equivalent to theft, and although they 
recognize the need for a minimal state, they argue for constitutional limits on taxing, spending, and regulating. 6 They assume that political power, not outright corruption, is the problem, but if government officials are self-interested revenue maximizers, it seems consistent with their model for those with political power to extract private benefits for themselves, risking a descent into outright kleptocracy. This extreme view is far from reality. Modern representative democracies are certainly imperfect, but they do manage to translate public preferences into practical policies. Most officials cannot or do not seek to exploit all opportunities for private gain. One can study corruption without succumbing to extreme cynicism about the kleptocratic or Leviathan state. Modern governments impose constitutional and institutional constraints that limit self-seeking, and the state can seek to attract individuals to public service careers who have the values needed to resist temptations to enrich themselves at state expense.

The libertarian approach seldom takes public institutions seriously as reflections of democratic and constitutional choices. One should not expect majoritarian democracies to produce fully efficient outcomes. They will reflect majority sentiment and the organizational ability of different groups. They are bound to produce 
some inefficient regulations and impose costs on some to benefit others. Nevertheless, in a well-functioning democracy, they represent legitimate, if imperfect, efforts to respect the will of the citizenry. So long as fundamental constitutional and human rights are respected, bad laws do not justify corrupt efforts to undermine their administration. One cannot defend oneself against a bribery charge by introducing into evidence a social science study that demonstrates a law's inefficiency. The libertarian defense of bribery as a way to avoid the demands of public officials trivializes and undermines democratic institutions.

\section{II. ethnography and corruption}

Cultural anthropologists also tend to be sympathetic to gifts and favors that others call corruption, but they reach that conclusion by a very different route. They study payments or gifts given to officials and the mutual exchange of favors, including electoral quid pro quos. They look to traditions that emphasize loyalties to friends, family, region, tribe, religion, or ethnic group. These practices privilege informal, friendly social contacts over arms-length, rule-bound transactions. Scholars in this tradition often refuse to label transactions as corrupt if they are based on affective ties, or 
they claim that, even if formally illegal, the practices are socially acceptable, economically beneficial, and compensate for the imperfections of government and of electoral institutions.

All modern states are dominated by a formal set of rules and laws administered by public officials and influenced by the choices of political leaders, whether elected or appointed. States may incorporate values and practices that clash with a society's traditions. If nepotism and payments in money or in kind are formally illegal, there may be a mismatch between traditional practices, on the one hand, and efforts to develop impersonal bureaucratic processes and democratic electoral systems, on the other. This disjunction is particularly acute if a society is making a transition from personalistic modes of interaction between rulers and the ruled to relationships based on arms-length, impersonal, professional interactions. Impartiality clashes with feelings of duty and loyalty to kin and in-group.

Many ethnographers have studied societies where corruption is intertwined in citizens' day-to-day experience with the public sector. Payoffs are not arm's-length transactions but are part of a social interaction. They mix economic motives and social practices. 7 
However, even if social norms help to justify the behavior, economic motives-for example. getting a government contract, or issuance of a business license-often motivate the transaction. Citizens may be paid to vote and pay to get access to education and health care. If they wish, for example, to register a property deed, obtain a telephone line, or obtain their pension checks, payoffs are routine in some societies. Avoiding costs, such as taxes and tariffs often requires a bribe. Actual or invented violations of the law lead to bribery demands from police or inspectors. In judicial proceedings, bribes assure a friendly judge, lower fines, and can lead to the "loss" of key documents. Thus, whatever the cultural explanations, the consequences for government functioning can be extremely detrimental.

Olivier de Sardan develops these themes in the African context. Social norms support interactions that outsiders see as corrupt but that the participants view as acceptable or even moral. The politically powerful are expected to receive tribute from their subjects. If politicians or public officials have the opportunity to enrich themselves, they have an obligation to do so and to share generously with those who helped them to advance. This puts civil servants in a bind. Their professional legitimacy arises from their 
training as public administrators on the European model, but their social legitimacy depends on conforming to local norms that clash with their training. Research on Ghana and Nigeria confirms this basic pattern.

In Ghana, Jennifer Hasty describes corruption as "an intensification of contact with the vital flows coursing through the political body," $\underline{9}$ and she notes the prevalence of metaphors of eating and of the flow of blood to describe the practice. Corruption is not seen as the impersonal market invading the state but rather as hyperengagement in already existing sociopolitical flows. In Nigeria, Daniel Jordon Smith finds corruption embedded in "everyday instances of patronage" that are related to networks of kin, community, and other interpersonal associations. Corruption that helps ones friends and kin "can look like moral behavior from local perspectives."10 As Smith concludes, a feedback loop perpetuates corruption. State offices are unreliable in delivering basic services. Yet, the use of clientelistic networks to deliver public resources based on "moral obligations and affective attachments" fuels a cycle of corruption. 11

Nevertheless, anthropological accounts report that most people 
recognize corruption as a deep problem even as they affirm the social bonds that it expresses. In Africa corruption is "as frequently denounced in words as it is practiced in fact." 12 There is a continuum "from bribing someone and thanking someone for services rendered." 13 Even though the briber often claims to have "good reason" for his actions, he also condemns the behavior of others who obtain benefits through payoffs and connections. Nigerians and Ghanaians are extremely critical of the level of corruption in their country, and they believe that it promotes the inequality of wealth and power.14 Ordinary people condemn corruption at the elite level, but they themselves participate in networks that socially reproduce corruption.

Similar ambiguity exists in China around the concept of guanxi, which literally means social relationships or social connections. Official pronouncements equate guanxi with bribery that undermines the public interest. However, "embodied in the popular discourse in the contradiction of the condemnation of guanxi on the one hand, and admiration and even approbation on the other." 15 Even as they condemn its prevalence, people brag about how they used guanxi to obtain benefits and refer to the ethics of obligation and reciprocity. 
One can surely sympathize with a person caught in a personalistic system based on bribery. Sympathy need not imply acceptance, however. Corruption is not the inevitable result of history and culture. Social norms may be deeply embedded and self-reinforcing, but they do sometimes change; they are not necessarily frozen in time. And, if a society is ever to build a legitimate democracy, norms must change. Otherwise, pervasive corruption will inexorably undermine respect for the rule of law, generating serious distortions in the efficiency and fairness of service delivery.

The underlying condemnation of corruption, even by those who make payoffs in their everyday lives, suggests openings for reform. Perhaps more public awareness of the costs of payments-whether labeled gifts or bribes-could change behavior and increase support for reform. For example, if some people pay to receive drivers' licenses even though they do not know how to drive, reform could begin by publicizing the extra accident risk. 16 If a social welfare program is corrupted by officials who demand payoffs, reform can give applicants a legal option--for example, through freedom of information act requests. 17 If politicians or political 
parties make direct payments to voters in return for support, voters need to see that the social cost is a weakening in the representative character of government.

Ethnographic research tends to concentrate on cultural and social expectations to explain the prevalence of personalistic ties and quid pro quo transactions, but these interactions are also tied to the bargaining power of officials. One must take both factors into account.

Ethnographers and libertarians who move beyond positive, empirical analyses of state/society relations often espouse strikingly similar normative positions. Both stress the way payoffs to public officials permit non-state institutions to flourish in spite of a set of formal rules that constrain private behavior. However, each gives a different set of institutions priority-social ties for one and the market for the other. Libertarians espouse a universalistic model of the idealized free market in contrast to the meddling state. They prefer a minimal state, but absent that condition, some types of payoffs may helpfully unleash market forces. The ethno-culturalists reject universalistic models of a good society and often criticize the corruption literature for its ideal of an impartial, professionally 
competent government. For both groups, corruption is an understandable response to a dysfunctional reality. Citizens may engage in rhetorical condemnation, but they cannot function as economic or social actors without such quid pro quo transfers. 18 Libertarians and the ethnographers frequently find common ground in arguing for the functionality of at least some payoffs, but they differ sharply on the values that these payoffs may further.

\section{III. grand corruption}

Corruption occurs in people's day-to-day lives and in routine business activities as people navigate their relationship to the state. However, of particular important is corruption at the top of the state hierarchy that involves political leaders and their close associates and concerns the award of major contracts, concessions and the privatization of state enterprises. Such "Grand corruption" imposes large costs on ordinary people by diverting funds to top political leaders in exchange for sweetheart deals with big foreign and domestic businesses. As a result, the government may purchase too much of the wrong kind of military equipment, award natural resource concessions on unfavorable terms, or privatize state-owned firms at too low a price. Grand corruption may induce 
leaders to support massive one-of-a-kind infrastructure projects that have little justification beyond their appeal as bribe generation machines. Defense contracting, infrastructure spending, and privatization, of course, are not illegal per se. The problem is the distortions in both quality and quantity introduced by corruption. In countries with elections some of kickbacks may be used to court voters under a variety of vote-buying schemes, but significant funds also flow to politicians' personal bank accounts. The costs of such high level corruption include distorted government spending priorities, the transfer of funds offshore that could otherwise benefit citizens, and unfair electoral advantages for incumbents.

Profit-oriented multinational firms sometimes invoke cultural arguments as a justification for making payoffs to top officials. They may defend their payoffs in reference to the host country's traditions of gift giving and deference to leaders. For example, a 2006 international arbitration dispute involved a \$2 million cash bribe paid to then President Daniel Arap Moi of Kenya. No one disputed the bribe, but the firm claimed that it was respecting the local East African custom of harambee and that gifts of this type were "fashionable" in Kenya. The Kenyan government, now under different leadership, contended that because of the bribe, no valid 
contract existed, implying that it was not guilty of breach. The arbitration tribunal sided with Kenya.19 A Transparency International-Kenya (TI-Kenya) study demonstrates that harambee, originally a type of communal self-help, has been converted into a form of patronage politics. It is common for politicians who seek reelection to pay for harambee events that may or may not actually take place.20 The multi-national firm's claims to be culturally sensitive ring hollow, especially in cases, such as this, where the nation's citizen bore most of the costs of the bribe and the unfavorable contract terms that it produced.

On the other side of such deals, top officials may go beyond a general invocation of local mores to justify their acceptance of payoffs as a tribute due to them because of their high official rank. They may use such arguments even if the scale of the gains is much beyond anything seen in traditional practices. 21 These self-serving arguments conflict with established traditions in many societies according to Mark Granovetter. In his view, top political leaders would honor tradition by rejecting bribes as insults, especially from multi-national firms lacking traditional ties.22 But, this is not what happens in cases of grand corruption. Instead, the bribe is often cloaked in traditional practices and facilitated by local 
agents.

A more straightforward culturalist argument sees high level or "grand" corruption as an import from wealthy, capitalist countries. It substitutes pure financial incentives for a dense network of in-country connections. Payoffs induce top leaders to sell out their political supporters in return for private gain or, in a somewhat more benign view, to benefit their own supporters at the expense of the broader public. A polity may already operate in a winner-take-all fashion with rotating in-groups using the state to benefit themselves and their supporters. If so, the opportunity to benefit from contracts, concessions, and asset sales can drastically increase the size of the pie. A resource discovery or a massive aid package supporting infrastructure construction may undermine a stable system of low-level rent seeking by top politicians. It increases the rents available and tempts leaders to collude with investors to share the wealth at public expense.

Ethnographers point to the power of the multi-national firms' profit motive as well as the traditional perquisites of political power in developing countries. However, most scholars with deep knowledge of particular cultures do not confuse explanation with excuse. For 
them, culture enters the argument once again, but now it is the culture of the business community with its profit-maximizing goal. The very motivator that the libertarian sees as central to the development of society is excoriated as the corrupter of the traditional culture of the contracting country.

Bribes, however, are a cost to firms that pay them. Firms and officials are in a bargaining game, and it is hard to assign blame when both must agree to the deal. From the cases that have come to light it seems that political leaders are not averse to using their bargaining power to extract private benefits. This observation leads some to claim that the values of the leaders have been corrupted by contact with the colonial powers. All would have been well if they had kept to their societies' traditional norms and practices. Of course, sophisticated ethnographers do not have such a romantic view of "culture" and recognize the interpenetration of Western and traditional values and practices. Reformers in developing countries criticize their compatriots who too easily blame an alien culture introduced by colonial powers for present day realities. As an Indonesian journalist put it recently: "If corruption is embedded in the culture, then it is not the fault of the Indonesians themselves -rather, it can be laid at the feet of those nasty Dutch colonialists . 
.. Not only does this fable get people off the hook for failing to solve the problem, . . . it also absolves the entire nation of guilt because the blame lies elsewhere in a long-distant colonial past." 23

The cultural sensitivity card can be played both by those who accept and by those who pay bribes when it serves their own interests. One needs to be cautious in accepting at face value assertions that seemingly corrupt transactions reflect entrenched cultural practices acceptable to most people. Those with something to gain will invoke culture as an excuse when it serves their self-interest. If the scale of the tribute paid to a leader rises to a new plane as a result of the involvement of international investors, tradition and culture are not adequate frames for analysis. The widespread condemnation of bribery and corruption in the studies of Ghana and Nigeria mentioned earlier seems to confirm that citizens generally do not accept glib references to "culture" or "social norms" as sufficient justification.

\section{IV. democratic legitimacy and the control of corruption}

The nation-state is a necessary part of any modern society, but one that must be constrained by its citizens to preserve public 
legitimacy. The state exercises coercive powers, and to claim to be a democracy, it must publicly justify its exercise of those powers. Democracy does not require unanimous consent to individual policies. Doing so would unduly privilege the status quo and invite gridlock. Rather the policymaking process will almost invariably produce winners and losers. The key is a process that is broadly acceptable even if individuals sometimes must bear the costs of a public policy without any corresponding gains. Decisionmaking by a majority of elected representatives is one route to democratic legitimacy, but it is not the only route and cannot realistically be the only locus of policymaking. Modern problems are too technically complex, too fluid, and require too much time and trouble to be fully resolved by statutory texts. Hence, delegation of policymaking is pervasive in all modern states. Even detailed statutory programs must be implemented by bureaucrats, perhaps with the help of private contractors. 24

But elected officials, political appointees and bureaucrats may engage in self-interested behavior that undermines the state's claim to legitimacy. Favors done in return for bribes are an archetypal example of such personalized transactions. The individual quid pro quo between official and citizen or business firm may be mutually 
beneficial, but collectively these transactions undermine confidence in the neutral generation and imposition of rules.

In some of the cases outlined earlier, however, impartiality is absent, and the exercise of public power is bound up with paternalistic obligations. In those cases, it is difficult to disentangle corrupt dealings from widely accepted social practices. However, one option is to demonstrate the costs as well as the benefits of mixing private concerns with the delivery of public services. If corruption is an accepted part of government transactions, then officials are not likely to be passive recipients of gifts from grateful citizens or of payoffs from business firms. Instead, bureaucrats are likely to organize their offices and rewrite the rules to induce additional payoffs, and politicians may structure their activities to generate ever larger bribes or illegal campaign donations. If this happens, non-state actors such as organized gangs, on the one hand, and benevolent associations, on the other, may substitute for a weak state. The tendency to operate outside the state may create a feedback loop that further weakens democratic legitimacy and state power.

The difficulty for democrats is that the economic incentives for 
corruption are the inevitable side effect of a system that governs through elected representatives and uses bureaucratic agents to carry out policies. They are pathologies, but they are also the predictable dark side of the modern state. If corruption is justified as a reflection of cultural norms, then such acquiescence will further compromise efforts to produce impartial and competent service delivery. The communitarian ideal of public deliberation and consensus combined with a moral obligation to comply with state policy is not realistic as a general matter once one moves beyond small villages or tight-knit communities. Tensions between the democratic welfare state and the private market and between that state and a country's traditional cultural practices are all but inevitable. The response need not always be in favor of the rationalized, Weberian state. Jennifer Hasty argues that global strategies that "attempt to tighten the grip of the modern rational state through abstract, bureaucratic practices of discipline . . . are bound to fail." Instead, policy should seek socio-cultural transformation that builds on existing patterns. 25

Anticorruption policy must decide whether to accept the presence of greed and of cultural practices and to seek to channel them into less destructive paths, whether to sideline them through substitute 
institutions that require other values and skills, or whether to seek to transform social norms. These issues must be confronted from the perspective of democratic legitimacy, not through the lens of either market fundamentalism or cultural preservation. One needs a realistic appreciation of the strains facing modern democracies that seek to justify their legitimacy. Corruption can undermine governments even if it aids market participants and supports traditional cultures. However, aggressive and punitive anticorruption campaigns can also undermine governments' ability to tap into the loyalty and good will of their populations.

Corruption in all its myriad forms arises at the intersection between culture, the market, and the state. Its prevalence forces us to confront the tangled connections between private wealth and public power and between cultural practice and the creation of a competent and impartial government. Sometimes sensitivity to culture and history in one society will lead to tolerance of actions that are labeled bribery in other societies. Sometimes public or private power is so rigid and oppressive that individual payoffs to avoid the rules seem the only feasible way to cope. Voters do not always punish flamboyantly corrupt politicians at the polls, presumably because no credible alternatives exist. It may seem 
better to tolerate an incumbent who takes a share of the spoils of office than to risk retaliation from the incumbent by supporting an untested challenger.

What response can those engaged in the study of corruption give to the critics of anticorruption efforts? As someone who has studied this topic for thirty-five years, 26 I have no easy answers, but I do have some pointed responses that can help shape the agenda for future research. None of the critics straightforwardly confronts the role of the state in society. At the extremes, they have a romantic view of an idealized society with a minimal state. For libertarians, the minimal state respects "the rule of law," a concept that in their formulation stresses the preservation of private property rights and the enforcement of private contracts, on the one hand, and the assurance of law and order, on the other. For ethnographers, social networks are the key to understanding how individuals interact with public officials. This literature seldom acknowledges the modern state's role in producing and maintaining these networks. Rather, the state is frequently seen as a hostile or interfering force that personal networks can domesticate through exchanges of favors. Those from this tradition who do study the state tend to urge more participatory, consensual processes of public decision-making often 
organized at the neighborhood and village level.

In contrast to both the libertarians and the ethnographers, I urge a straightforward acknowledgment of the centrality of the modern bureaucratic state and the institutions of representative government.Furthermore, even authoritarian regimes seek popular legitimacy and support. Given those premises, one can locate areas of broad international agreement, both at the grass roots level and among the elite, on certain desirable characteristics of the modern state that can help curb corruption. So long as political leaders have some interest in reform, anticorruption policy can start with these areas of agreement and later confront the more contested dimensions of the problem.

First, simple transparency is necessary. This option requires publication of and easy public access to the constitution, legal codes and statutes, regulations and decrees with the force of law, legal guidelines and practice manuals, and judicial opinions. Officials charged with implementation may resist revealing guidelines and practice manuals, but if they have real effects within the agency, outsiders should be able to access them. Furthermore, there should be standardized and transparent public accounting for 
funds appropriated and spent by the government under the control of both an internal audit office and an independent external audit body.

Second, external oversight of government activity is essential. One route is to remove press restrictions and sponsor training in investigative journalism. It should also be easy to establish and finance civil society organizations. These dual oversight tracks complement each other in practice and can only function effectively if the government itself provides information under the first type of reforms above. For example, in Bolivia a World Bank study showed that the quality of public service delivery was negatively associated with corruption and positively associated with external oversight and transparency. 27 Here authoritarian regimes will part company with reformers in democracy, but even the Chinese government has recognized the value of routes for citizen complaints even as it limits other forms of oversight and protest.

Third, to counter grand corruption, transparent and competitive processes for large scale procurement should exist. But governments should not fetishize competitive bidding. They should take realistic account of the occasional need for sole-source 
procurement. In that case, the negotiations should be transparent with the focus on the government obtaining a high quality result at a good price. Purchases should as much as possible be made by shopping in private markets in competition with private buyers. Here international efforts to provide benchmark prices for common procurement needs could complement domestic efforts.As an example of how benchmarking might work, one study calculated the large relative differences in public infrastructure prices by region in Italy with the implication that regions with high costs per unit were experiencing high corruption and that better oversight could improve the productivity of public funds. 28

Fourth, the state should enforce bribery laws against major offenders both in and outside of government. If organized crime is pervasive, special efforts will be needed to apprehend those involved in corruption that permits such crime to flourish. I list the law enforcement option fourth, however, because it ought never be the primary means of fighting entrenched corruption. If corruption is the result of institutional failures, it will likely reappear as one group of malefactors is replaced with another.

Fifth, individuals and businesses should be able to lodge 
complaints about demands for bribes or other favors and to have these complaints expeditiously dealt with-for example, through an independent ombudsman. Sixth, reformers should make diagnostic studies of the rules, regulations, and licensing requirements facing individuals and businesses to isolate reforms-including repeal-that might both improve government functioning and reduce corruption. Seventh, it may be important to improve the pay, recruitment, and working conditions of civil servants and the judiciary. Such reform should be combined with strengthened conflict-of-interest rules and internal monitoring of public service delivery.

Finally, if corruption is pervasive among politicians, electoral law may need reform. That would involve enforcement of laws that outlaw the buying of individual votes and improvements in the system of campaign finance, the role of lobbyists, and the private financial interests of politicians to limit conflicts of interest.

Much has been made recently of the efforts to control corruption through international treaties $\underline{29}$ and civil society initiatives, such as those spearheaded by Transparency International ( $\mathrm{TI}$ ) and the Extractive Industries Transparency Initiative (EITI). 30 The G20 in its 
June 2010 communique recognized that corruption is a global problem. 31 This international concern is a welcome development that can complement and reward efforts within host countries, especially to combat grand corruption by multi-national businesses. However, existing initiatives have little real bite as hard law. Their impact depends upon changing mores and on bad publicity, not legal penalties. These international efforts, laudable as they are, cannot substitute for domestic reform. Constraining the willingness of multi-national firms to pay bribes under the OECD Convention will help undermine firms' claims to cultural sensitivity, but these effects can only complement, not substitute for domestic reform.

In discussing corruption, we need to move beyond simplistic claims either that corruption is functional because government is dysfunctional or that corruption in a Western concept used to belittle or to undermine cherished cultural traditions. Both statements are true in some contexts and false in others. Domestically, reformers need to concentrate on the policies that enhance the competent development of public policy, the effective delivery of services by the bureaucracy, and the fair resolution of disputes in the courts. They should begin with the functional responsibilities of the state and then ask how bribery and 
self-dealing interfere with these goals. They should not start with a presumption against the state born either of excessive faith in the market or of a deeply conservative respect for tradition.

Representative democracy, bureaucracy, and the courts are facts of modern life. The study of corruption can help mediate the state and society boundary but cannot eliminate it. The state is here to stay, whatever romantics on the libertarian right or on the cultural-studies left might wish. We had better stop bemoaning that fact and instead seek realistic reforms that balance state capacity and political will. 